\title{
Produção de feijão-caupi sob efeito de veranico nos sistemas de plantio direto e convencional
}

\section{Cowpea production as affected by dry spells in no-tillage and conventional crop systems}

\author{
Rômulo Magno Oliveira de Freitas ${ }^{1 *}$; Jeferson Luiz Dallabona Dombroski; \\ Francisco Cláudio Lopes de Freitas ${ }^{2}$; Narjara Walessa Nogueira ${ }^{1}$; \\ Igor Julyetson Silva Procópio 3
}

\begin{abstract}
Resumo
O objetivo do presente trabalho foi avaliar o efeito de diferentes períodos de deficiência hídrica, nos sistemas de plantio direto e convencional, sobre os componentes de produção e rendimento de grãos de feijão-caupi, na Região de Mossoró-RN. Para isso, foi realizado um experimento utilizando-se dois sistemas de plantio (convencional e direto) submetidos a períodos de suspensão da irrigação $(2 ; 6 ; 10$; 14; 18 e 22 dias), iniciados por ocasião do florescimento (34 dias após a semeadura). A colheita foi realizada aos 70 dias após a semeadura, sendo colhida uma das linhas da área útil, correspondendo a uma linha de $4 \mathrm{~m}$ por subparcela, as variáveis avaliadas foram: comprimento de vagens (CV); número de grãos por vagem (NGV); número de vagens por planta (NVP); peso de cem grãos em gramas (PCG) e rendimento de grãos $\left(\mathrm{kg} \mathrm{ha}^{-1}\right)$. O sistema de plantio direto é mais produtivo do que o convencional sob irrigação e em condição de estresse. Os períodos de veranico influenciaram negativamente o rendimento de grãos e todos os componentes de produção estudados, com exceção do peso de cem grãos. Entre os sistemas estudados, o plantio direto foi o que proporcionou maiores valores para os componentes de produção, exceto peso de cem grãos.

Palavras-chave: Vigna unguiculata (L.) Walp, cobertura do solo, estresse hídrico, rendimento de grãos, componentes de produção
\end{abstract}

\begin{abstract}
The objective of this study was to evaluate the effect of different periods of water shortage in notillage and conventional crop systems on cowpea yield components and grain yield in the Mossoró-RN region. For this, an experiment was conducted using two tillage systems (conventional and no-tillage) subjected to periods of irrigation suspension $(2 ; 6 ; 10 ; 14 ; 18$ end 22 days), started at flowering (34 days after sowing). Plants were harvested 70 days after sowing, and the studied variables were: Pods length $(\mathrm{CV})$, number of grains per pod (NGV), number of pods per plant (NPP), the hundred grains weight $(\mathrm{PCG})$ and grain yield $\left(\mathrm{kg} \mathrm{ha}^{-1}\right)$. The no-tillage system is more productive than the conventional under both irrigation and water stress treatments. The water stress length affected grain yield and all yield components studied in a negative way, except for the hundred grains weight. Among the systems studied, the no-tillage provides higher values for the yield components, except the hundred grains weight.
\end{abstract}

Key words: Vigna unguiculata (L.), ground cover, water stress, grain yield, yeld components

1 Discentes do Curso de Doutorado em Fitotecnia pela Universidade Federal Rural do Semi-Árido, UFERSA, Mossoró, RN. E-mail: romulomagno_23@hotmail.com; narjarawalessa@yahoo.com.br

2 Profs. do Dept ${ }^{\circ}$ de Ciências Vegetais da UFERSA, Mossoró, RN. E-mail: jeferson@ufersa.edu.br; fclaudiof@yahoo.com.br

${ }^{3}$ Eng $^{\circ}$ Agr $^{\circ}$, UFERSA, Mossoró, RN. E-mail: igor.procopio1@hotmail.com

* Autor para correspondência 
O Nordeste do Brasil é uma importante região tropical do mundo, contando com uma área de cerca de 1,6 milhões de $\mathrm{km}^{2}$, onde mais de 30 milhões de pessoas vivem em regiões semiáridas. A agricultura é principalmente de sequeiro, com produção de culturas de subsistência, como a do feijão-caupi (Vigna unguiculata (L.) Walp), que apresenta significativa importância socioeconômica como suprimento alimentar, na fixação de mão de obra no campo e como componente da produção agrícola (BEZERRA et al., 2008; ROCHA et al., 2009).

Um dos grandes problemas encontrados nessa Região é a irregularidade das chuvas, que faz com que a média do rendimento dessa cultura em sistemas de sequeiro fique entre $300-700 \mathrm{~kg} \mathrm{ha}^{-1}$, valor menor do que o rendimento de feijão cultivado em condições hídricas adequadas. Além da deficiência hídrica, provocada pela irregularidade das chuvas, altas temperaturas associadas a períodos críticos, como na fase de florescimento, provocam redução drástica do rendimento de grãos, aumento da respiração e redução da fotossíntese (BEAVER et al., 2003; MENDES et al., 2007).

A cultura do feijão-caupi tem sido mais pesquisada nos últimos anos, o que tem contribuído para melhorar sua produtividade e rentabilidade, o que, aliado a outros fatores, vem aumentando o interesse de médios e grandes produtores pela cultura (BEZERRA et al., 2008; FREIRE FILHO et al., 2005).

Diversos estudos foram realizados a fim de avaliar o efeito do déficit hídrico no rendimento e/ ou componentes produtivos do feijão-caupi, como os realizados por Cordeiro et al. (1998); Leite e Virgens Filho (2004); Mendes et al. (2007) e Nascimento, Pedrosa e Tavares Sobrinho (2004). Os estudos realizados até o momento abordam efeitos provocados pela deficiência hídrica. É preciso, porém, que haja estudos relacionados a técnicas que possibilitem a manutenção da produtividade mesmo em períodos sem chuvas.
Entre as práticas que podem ser estudadas destaca-se o sistema de plantio direto, considerado promissor para a cultura do caupi, por utilizar resíduos de cultura para cobertura do solo com a finalidade de manter a umidade deste, podendo ser uma alternativa na diminuição do risco da cultura ao déficit hídrico. Outra vantagem é a redução da temperatura do solo, muito alta na região Nordeste, com a proteção da palhada no solo contra os raios solares, ou seja, o plantio direto reduz o efeito drástico das condições climáticas desfavoráveis ao desenvolvimento da cultura (SIMIDU et al., 2010).

Sendo assim, o objetivo deste trabalho foi avaliar o efeito de diferentes períodos de deficiência hídrica, nos sistemas de plantio direto e convencional, sobre componentes produtivos e rendimento de feijãocaupi.

O experimento foi conduzido na horta do Departamento de Ciências Vegetais da Universidade Federal Rural do Semi-Árido (UFERSA), em Mossoró-RN, entre setembro e dezembro de 2011, em solo classificado como Argissolo Vermelho Amarelo Eutrófico. O município de Mossoró-RN está localizado no Nordeste brasileiro e possui coordenadas geográficas $5^{\circ} 11^{\prime}$ de latitude sul, 37 - 20 ' de longitude W. Gr., com 18 m de altitude. Durante a condução do experimento verificou-se temperaturas médias de $27^{\circ} \mathrm{C}$ e umidade relativa do ar média de $65 \%$.

Foi utilizado o delineamento experimental em blocos casualizados completos, no esquema de parcelas subdivididas e quatro repetições. Nas parcelas, foram avaliados dois sistemas de plantio (convencional e direto) e nas subparcelas, seis períodos de suspensão da irrigação $(2 ; 6 ; 10 ; 14 ; 18$ e 22 dias). A aplicação dos tratamentos (suspensão da irrigação) foi feita por ocasião do florescimento, período em que $70 \%$ das plantas apresentaram no mínimo uma flor, aos 34 dias após a semeadura (DAS). As parcelas foram constituídas por quatro linhas de $5 \mathrm{~m}$ de comprimento, espaçadas de 0,5 $\mathrm{m}$, tendo como área útil as duas linhas centrais, 
descartando-se $0,5 \mathrm{~m}$ em cada uma das extremidades. Visando garantir o isolamento, cada subparcela foi separada por um metro.

A área utilizada foi cultivada nos sistemas de plantio direto e convencional nos quatro anos anteriores à instalação do experimento. Para obtenção da palhada, no início do período chuvoso, no sistema de plantio direto, foi realizado o plantio com Brachiaria brizantha. 30 dias antes da instalação do experimento. Foi realizada dessecação de $B$. brizantha com $1,90 \mathrm{~kg} \mathrm{ha}^{-1}$ do herbicida glyphosate.

Nas áreas destinadas ao plantio convencional, foi realizado preparo do solo por meio de uma aração e duas gradagens. Da área onde foi conduzido o experimento, foi retirada uma amostra composta de solo a uma profundidade de até $20 \mathrm{~cm}$ para análise química a fim de determinar a adubação. As seguintes caracterizações químicas do solo foram verificadas: $\mathrm{pH}$ (água) de 6,1; teor de matéria orgânica de 11,5 g/kg; fósforo $(\mathrm{P})$ de $173,7 \mathrm{mg} / \mathrm{dm}^{3}$; potássio $\left(\mathrm{K}^{+}\right)$de $158,8 \mathrm{mg} / \mathrm{dm}^{3}$; cálcio $\left(\mathrm{Ca}^{2+}\right)$ de $3,52 \mathrm{cmol} \mathrm{c} / \mathrm{dm}^{3}$; magnésio $\left(\mathrm{Mg}^{2+}\right)$ de $1,02 \mathrm{cmol} \mathrm{c} /$ $\mathrm{dm}^{3}$ e alumínio $\left(\mathrm{Al}^{3+}\right)$ de $0,17 \mathrm{cmol} \mathrm{c} / \mathrm{dm}^{3}$.

Após o preparo do solo e demarcação do experimento, foi instalado o sistema de irrigação por gotejamento na linha de plantio, com emissores de $1,7 \mathrm{~L} \mathrm{~h}^{-1}$ espaçados de $0,3 \mathrm{~m}$. A fim de evitar diferenças no fornecimento de água para os tratamentos, foram feitas leituras diárias de tensiômetros instalados, de forma casualizada, com dois tensiômetros por tratamento, a $20 \mathrm{~cm}$ de profundidade. Para o controle da irrigação, em cada subparcela foi utilizado um registro.

A cultivar de feijão-caupi utilizada foi o BRS Guariba, de crescimento semiereto, destinado à produção de grãos secos. A semeadura e adubação foram realizadas com utilização de uma matraca, regulada para duas a quatro sementes por cova e $250 \mathrm{~kg} \mathrm{ha}^{-1}$ de NPK na formulação 6-24-12. O espaçamento adotado foi de $0,3 \mathrm{~m}$ entre covas e 0,5 $\mathrm{m}$ entre linha. Após a emergência, foi realizado o desbaste, deixando duas plantas por cova.
No sistema de plantio convencional o controle de plantas daninhas foi realizado manualmente com utilização de enxadas, com capinas realizadas aos 15 e 30 DAS. No sistema de plantio direto as plantas daninhas foram roçadas aos 25 DAS, de forma localizada.

A colheita foi realizada aos 70 DAS e foram avaliadas as características agronômicas: a) comprimento de vagens $(\mathrm{CV}, \mathrm{cm})$ - determinada pela medição do comprimento, de 10 vagens por subparcela; b) número de grãos por vagem (NGV) - realizada pela contagem do número de grãos das mesmas vagens da variável anterior; c) número de vagens por planta (NVP) - dividindo-se o número total de vagens pelo de plantas da área útil; d) peso de 100 grãos em grama (PCG); e) rendimento de grãos $\left(\mathrm{kg} \mathrm{ha}^{-1}\right)$ - foi determinado o peso de grãos por planta em gramas (PGP), dividindo-se o peso de grãos pelo número de plantas encontradas na área útil. O peso de grãos, em $\mathrm{kg}$, por área útil, foi corrigido para $13 \%$ de umidade - [(100-Hi) x PG]/ (100-Hf), onde Hi: umidade de grãos determinada em estufa a $105^{\circ} \mathrm{C}$ por $24 \mathrm{~h}$; Hf: umidade de grãos que deve ser corrigida (13\%) e PG produção de grãos na área útil. Com esses valores, foi determinado o rendimento de grãos $\left(\mathrm{kg} \mathrm{ha}^{-1}\right)$ - calculado por $\mathrm{RG}=$ $\left(10.000 \mathrm{~m}^{2} \mathrm{x}\right.$ PGC kg)/área útil $\mathrm{m}^{2}$, onde PGC é o peso de grãos corrigido a $13 \%$ de umidade da área útil experimental.

Os resultados foram submetidos à análise de variância pelo teste $\mathrm{F}$, a $5 \%$ de probabilidade, com o auxílio do programa estatístico SISVAR. As regressões foram geradas utilizando-se o software Sigmaplot 11.0. Na escolha do modelo, levou-se em conta a explicação biológica e a significância do quadrado médio da regressão. Foi feita análise de correlação de Pearson dos valores de rendimento de grãos, nos períodos de estresse, com os componentes de produção.

Entre os sistemas de plantio, houve efeito significativo para as variáveis número de grãos por vagem $(\mathrm{NGV})$, comprimento de vagens (CV), 
número de vagens por planta (NVP) e rendimento de grãos (RG), não sendo verificado efeito significativo para peso de cem grãos (PCG). Os períodos de veranico promoveram alterações significativas em todas as características produtivas e rendimento de grãos.

Houve interação entre os sistemas de plantio e os períodos de veranico para todas as variáveis, exceto peso de cem grãos. Aos 2 e 4 dias sem irrigação, os sistemas de plantio não influenciaram o comprimento das vagens, sendo que para o plantio direto este comportamento ocorreu aos 10 dias de veranico (Figura 1.A). No sistema convencional, com 10 dias de veranico, ocorreu uma redução de $7,8 \%$ no comprimento das vagens. Deste período em diante, o sistema de plantio direto, para todos os períodos de veranico, foi superior ao sistema convencional para a característica estudada, com perdas relativas de 6,$8 ; 20,4$ e $25,5 \%$ para o plantio direto e 16,$8 ; 29,9$ e $34,9 \%$ para o convencional, aos 14,18 e 22 dias sem irrigação, respectivamente.

Vagens de plantas cultivadas no sistema de plantio direto conseguiram permanecer com o mesmo tamanho por um tempo sem irrigação superior ao registrado no sistema convencional. Este foi o maior motivo para a ocorrência de maior comprimento médio das vagens em plantas de feijão-caupi semeadas no sistema de plantio direto do que registrado no sistema convencional. Nascimento, Pedrosa e Tavares Sobrinho (2004), trabalhando com a cultivar IPA 206 de feijão-caupi em Areia-PB e em estufa, também encontraram redução do comprimento de vagem de $8 ; 16$ e 24\%, correspondentes aos níveis de 80;60 e 40\% da água disponível no solo. Já Mendes et al. (2007), trabalhando com estresse hídrico em duas cultivares de caupi, em Fortaleza-CE, e Oliveira et al. (2011), em trabalho realizado no cerrado de Roraima com diferentes lâminas de irrigação na mesma cultura, verificaram que a deficiência hídrica não exerceu influência sobre o comprimento de vagem.

Quanto ao número de sementes por vagem, os sistemas de plantio apresentaram respostas semelhantes aos 2 dias de veranico, mostrando que, nesta condição, o número de sementes por vagem (Figura 1.B) não é uma característica afetada pelo sistema de plantio.

Da mesma forma que ocorreu para comprimento de vagens, verificou-se diferença para o número de grãos por vagem apenas após os 10 dias, com o sistema de plantio direto mantendo o número de grãos e o convencional com uma redução de, em média, 2 grãos por vagem $(15,8 \%)$, diferença que permaneceu até o maior período de veranico. Nos períodos de 14, 18 e 22 dias sem irrigação, verificaram-se, para os sistemas de plantio direto e convencional, perdas relativas de $4 ; 25$ e 39, e 31; 48 e $58 \%$, respectivamente. Em trabalho realizado no município de Santo Antônio de Goiás, Goiás, com a cultura do feijoeiro (Phaseolus vulgaris L.), variedade Pérola, em sistema de plantio direto, Andrade et al. (2002) constataram que todos os componentes da produção não diferiram estatisticamente do tratamento sem cobertura do solo, com valores do número de grãos por vagem de 5,4 a 6,6 , respectivamente.

Plantas de feijão-caupi submetidas a diferentes períodos de veranico apresentaram o maior número de vagens por planta (Figura 1.C) quando submetidas ao sistema de plantio direto, resultado observado até os 18 dias de veranico. Após esse período, verificou-se que os sistemas não mais diferiam. Aos dois dias sem irrigação, verificou-se que o número de vagens do sistema de plantio direto foi de 8,7 e no sistema de plantio convencional esse valor foi de 5,9 , representando incremento de aproximadamente 3 vagens por planta. Nascimento, Pedrosa e Tavares Sobrinho (2004) verificaram que o componente número de vagens por planta foi afetado pelo estresse hídrico e mais acentuadamente do que o ocorrido nos outros componentes de produção, em todos os níveis de déficit hídrico impostos pelos tratamentos.

Para Mendes et al. (2007), a ocorrência de deficiência hídrica resultou em reduções no número e peso de sementes por planta. Em média, essas 
perdas ocorreram de forma semelhante para as duas variáveis, em torno de $37,5 \%$ quando o déficit hídrico foi aplicado na fase vegetativa e de $49,0 \%$ na fase reprodutiva, mostrando que a fase reprodutiva foi a mais crítica. Como estes autores não encontraram diferença no número de grãos por vagem, pode-se afirmar que a redução no número e peso de grãos por planta deveu-se à redução, em condições de deficiência hídrica, do número de vagens por planta.

Quanto aos sistemas de plantio, esses resultados corroboram aos obtidos em estudo realizado por Bizari et al. (2009), em Campinas-SP, que, avaliando o consumo de água e produção de grãos do feijoeiro ( $P$. vulgaris L.) irrigado em sistemas plantio direto e convencional, observaram que entre os componentes da produção, os sistemas de manejo do solo não afetaram significativamente esses parâmetros, exceto para o número de vagens, que foi maior nas plantas do feijoeiro em sistema de plantio direto, diferindo estatisticamente do sistema convencional $(8,44)$, com um incremento de três vagens por planta no primeiro. Os resultados diferem também dos encontrados por Andrade et al. (2002), que, trabalhando com o feijoeiro em plantio direto e convencional, não verificaram diferença significativa para esta variável.

Embora os sistemas de manejo tenham apresentado diferenças para todas as variáveis analisadas, o peso de cem grãos (Figura 1.D) parece não ser uma característica influenciada pelos sistemas de manejo, com valores médios de 20,57 e 20,60, para os sistemas de plantio direto e convencional. Esta é, porém, uma variável modificada pelo período de veranico, com resultados melhores justamente nos períodos de maiores decréscimos das variáveis estudadas até o momento, aos 10 e 14 dias de estresse, e piores resultados com o maior fornecimento hídrico. Esses resultados são diferentes dos encontrados por Mendes et al. (2007), que não verificaram efeito entre os períodos de estresse hídrico.

Observa-se na Figura 1.E que ocorreu decréscimo no rendimento de grãos com o aumento do tempo de veranico, resultado observado para os dois sistemas, sendo verificadas perdas de 1372 e $1210 \mathrm{~kg} \mathrm{ha}^{-1}$ para plantio direto e convencional, respectivamente, entre o menor e o maior período de veranico. Oliveira et al. (2011), avaliando lâminas de irrigação na cultura do caupi, observaram que a menor lâmina de irrigação aplicada $(187 \mathrm{~mm})$ reduziu consideravelmente a produção de grãos $(43,3 \%)$, em comparação com a maior lâmina $(273,4 \mathrm{~mm})$.

Ocorreu diferença significativa para todos os períodos de veranico estudados, com maiores rendimentos obtidos no sistema de plantio direto. Aos 2 dias sem irrigação, a produção de grãos foi de 2234,16 e $1705 \mathrm{~kg} \mathrm{ha}^{-1}$, correspondendo aos sistemas de plantio direto e convencional, um ganho de 24\%. Não existem trabalhos na literatura mostrando a produtividade do feijão-caupi em plantio direto, embora existam indicativos da produção dessa cultura na entressafra da soja e outras culturas na região Centro-Oeste com cultivo altamente tecnificado. Para plantio convencional, o rendimento obtido foi superior ao encontrado por Freitas et al. (2009), que obtiveram rendimento de $1350 \mathrm{Kg} \mathrm{ha}{ }^{-1}$ na mesma região e de Oliveira et al. (2011), que obtiveram $1420 \mathrm{Kg} \mathrm{ha}^{-1}$. 
Figura 1. Comprimento de vagem (A), número de grãos por vagem (B), número de vagens por planta (C), peso de cem grãos (D) e rendimento de grãos (E) de feijão-caupi submetido a diferentes períodos sem irrigação $(2 ; 6 ; 10 ; 14 ; 18$ e 22 dias após o florescimento) nos sistemas de plantio direto e convencional. Mossoró/RN, UFERSA, 2011.
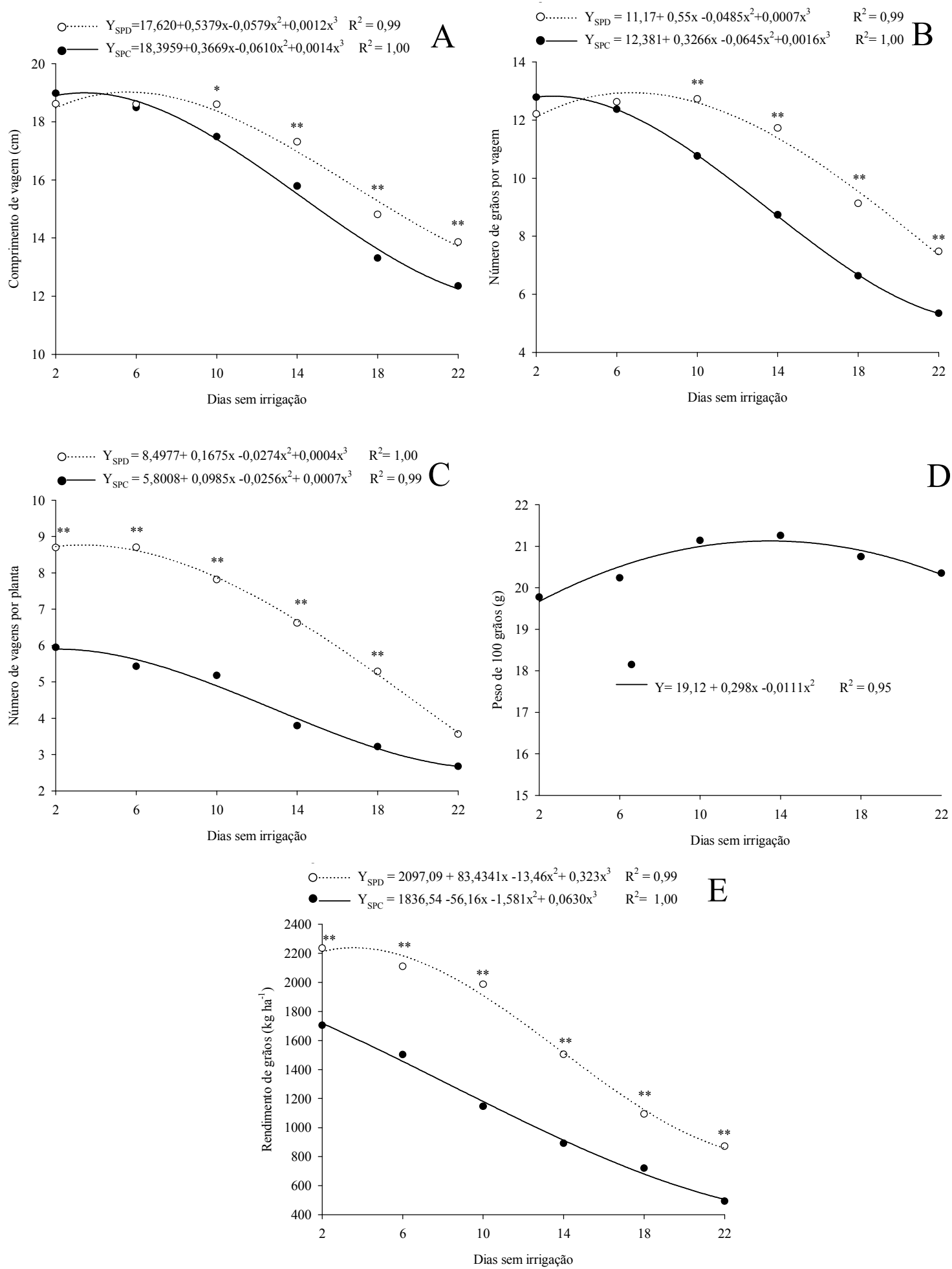

Pontos indicam média de quatro repetições e os asteriscos $(* *)$ e $(*)$ diferença significativa ao nível de 1 e $5 \%$ de probabilidade, pelo teste F.

Fonte: Elaboração dos autores. 
A redução do rendimento de grãos, observada entre os sistemas, foi de $12 ; 33 ; 48 ; 58$ e $71 \%$ para o convencional e $6 ; 11 ; 32 ; 51$ e $60 \%$ para o direto, aos $6 ; 10 ; 14 ; 18$ e 22 dias de veranico, respectivamente. Observa-se que as perdas do sistema de plantio convencional foram superiores a $30 \%$ após os 10 dias sem irrigação. Este valor só foi verificado para o sistema direto após os 14 dias, mostrando uma tolerância ao veranico de 4 dias do sistema de plantio direto em comparação ao convencional.

Os melhores resultados alcançados no sistema de plantio direto podem estar relacionados à maior retenção de água no solo coberto com palhada, à redução da temperatura máxima e à diminuição das oscilações de temperatura do sistema, fato também verificado por Andrade et al. (2002), Bizari et al. (2009), Simidu et al. (2010).
Bizari et al. (2009) obtiveram para o feijoeiro uma produtividade no sistema de plantio direto de $2.337 \mathrm{~kg} \mathrm{ha}^{-1}$, superando em $36,2 \%$ a obtida no convencional (1.492 $\mathrm{kg} \mathrm{ha}^{-1}$ ), e maior eficiência do uso da água, com melhora de $45 \%$. O autor ressalta a importância da cobertura morta no processo de diminuição da evaporação da água no solo, com consequente aumento da disponibilidade de água para as plantas em comparação com o sistema convencional.

Pode-se observar que todos os componentes de produção, com exceção do peso de cem grãos, apresentaram correlação positiva com o rendimento de grãos (Tabela 1).

Tabela 1. Coeficientes de correlação de Pearson dos valores de rendimento de grãos $\left(\mathrm{RG}, \mathrm{kg} \mathrm{ha}^{-1}\right)$ em períodos de veranico $(2 ; 6 ; 10 ; 14 ; 18$ e 22), com os valores dos componentes de produção, peso de 100 grãos (PCG, g), comprimento de vagem $(\mathrm{CV})$, número de grãos por vagem $(\mathrm{NGV})$ e número de vagens por planta de feijão-caupi (NVP), nos sistema de plantio direto (SPD) e convencional (SPC). Mossoró/RN, UFERSA, 2011.

\begin{tabular}{ccc}
\hline \multirow{2}{*}{ Componentes de produção } & \multicolumn{2}{c}{ RG } \\
\cline { 2 - 3 } & SPD & SPC \\
\hline PCG & $-0,523^{\text {ns }}$ & $-0,372^{\text {ns }}$ \\
CV & $0,972^{* *}$ & $0,962^{* *}$ \\
NGV & $0,930^{* *}$ & $0,980^{* *}$ \\
NVP & $0,984^{* *}$ & $0,974^{* *}$ \\
\hline
\end{tabular}

${ }^{* *}$ Significativo ao nível de $1 \%$ de probabilidade.

n.s Não significativo.

Fonte: Elaboração dos autores.

Estes resultados estão de acordo, exceto peso de cem grãos, com os obtidos por outros pesquisadores, que afirmam haver uma tendência de incremento no rendimento de grãos através do aumento dos componentes de produção, como número de vagens por planta, grãos por vagem e peso de 100 grãos, demostrando relação direta entre esses componentes e a produção. O número de vagens por planta, por exemplo, tem sido utilizado, atualmente, para se efetuar a seleção indireta em gerações segregantes de feijão, por ser de fácil determinação e apresentar correlação alta e positiva com a produtividade (ARF et al., 2011; COELHO et al., 2002; FURTADO et al., 2002).

O feijão-caupi cultivado no sistema de plantio direto foi mais produtivo do que quando cultivado no sistema de plantio convencional quando em irrigação e sob condição de estresse. Os períodos de veranico influenciaram negativamente o rendimento de grãos e todos os componentes de produção estudados, com exceção do peso de cem grãos. Entre os sistemas estudados, o plantio direto foi o que proporcionou maiores valores para os componentes de produção, exceto peso de cem grãos. 


\section{Agradecimentos}

À Coordenação de Aperfeiçoamento de Pessoal de Nível Superior (CAPES), pela concessão de bolsa ao primeiro autor.

\section{Referências}

ANDRADE, R. S.; MOREIRA, J. A. A.; STONE, L. F.; CARVALHO, J. A. Consumo relativo de água do feijoeiro no plantio direto em função da porcentagem de cobertura morta do solo. Revista Brasileira de Engenharia Agrícola e Ambiental, Campina Grande, v. 6, n. 1, p. 35-38, 2002.

ARF, M. V.; BUZETTI, S.; ARF, O.; KAPPES, C.; FERREIRA, J. P.; GITTI, D. C.; YAMAMOTO, C. J. T. Fontes e épocas de aplicação de nitrogênio em feijoeiro de inverno sob sistema plantio direto. Pesquisa Agropecuária Tropical, Goiânia, v. 41, n. 3, p. 430-438, 2011.

BEAVER, J. S.; ROSAS, J. C.; MYERS, J.; ACOSTA, J.; KELLY, J. D.; NCHIMBI-MSOLLA, S.; MISANGU, R.; BOKOSI, J.; TEMPLE, S.; ARNAUD-SANTANA, E.; COYNE, D. P. Contributions of the bean/cowpea CRSP to cultivar and germplasm development in common bean. Field Crop Research, Amsterdam, v. 82, n. 2-3, p. 2-3, 2003.

BEZERRA, A. A. C.; TÁVORA, F. J. A. F.; FREIRE FILHO, F. R.; RIBEIRO, V. Q. Morfologia e produção de grãos em linhagens modernas de feijão-caupi submetidas a diferentes densidades populacionais. Revista de Biologia e Ciências da Terra, João Pessoa, v. 8, n. 1, p. 85-93, 2008.

BIZARI, D. R.; MATSURA, E. E.; ROQUE, M. W.; SOUZA, A. L. Consumo de água e produção de grãos do feijoeiro irrigado em sistemas plantio direto e convencional. Ciência Rural, Santa Maria, v. 39, n. 7, p. 2073-2079, 2009.

COELHO, A. D. F.; CARDOSO, A. A.; CRUZ, C. D.; ARAÚJO, G. A. A.; FURTADO, M. R.; AMARAL, C. L. F. Herdabilidades e correlações da produção do feijão e dos seus componentes primários, nas épocas de cultivo da primavera-verão e do verão-outono. Ciência Rural, Santa Maria, v. 32, n. 2, p. 211-216, 2002.

CORDEIRO, L. G.; BEZERRA, F. M. L.; SANTOS, J. J. A.; MIRANDA, E. P. Fator de sensibilidade ao déficit hídrico da cultura do feijão caupi (Vigna unguiculata (L.) walp.). Revista Brasileira de Engenharia Agrícola e Ambiental, Campina Grande, v. 2, n. 2, p. 153-157, 1998.
FREIRE FILHO, F. R.; RIBEIRO, V. Q.; ALCÂNTARA, J. P.; BELARMINO FILHO, J.; ROCHA, M. M. BRS Marataoã: nova cultivar de feijão-caupi com grão tipo sempre-verde. Revista Ceres, Viçosa, v. 52, n. 303, p. 771-777, 2005.

FREITAS, F. C. L.; MEDEIROS, V. F. L. P.; GRANGEIRO, L. C.; SILVA, M. G. O.; NASCIMENTO, P. G. M. L.; NUNES, G. H. Interferência de plantas daninhas na cultura do feijão-caupi. Planta Daninha, Viçosa, v. 27, n. 2, p. 241-247, 2009.

FURTADO, R. M.; CRUZ C. D.; CARDOSO, A. A.; COELHO, A. D. F.; PETERNELli, L. A. Análise de trilha do rendimento do feijoeiro e seus componentes primários em monocultivo e em consórcio com a cultura do milho. Ciência Rural, Santa Maria, v. 32, n. 2, p. 217 220, 2002.

LEITE, M. L.; VIRGENS FILHO, J. S. Produção de matéria seca em plantas de caupi (Vigna unguiculata (L.) Walp) submetidas a déficits hídricos. Ciências Exatas e da Terra, Ciências Agrárias e Engenharias, Ponta Grossa, v. 10, n. 1, p. 43-51, 2004.

MENDES, R. M. S.; TÁVORA, F. J.A. F.; PITOMBEIRA, J. B.; NOGUEIRA, R. J. M. C. Relações fonte-dreno em feijão-de-corda submetido à deficiência hídrica. Revista Ciência Agronômica, Fortaleza, v. 38, n. 1, p. 95-103, 2007.

NASCIMENTO, J. T.; PEDROSA, M. B.; TAVARES SOBRINHO, J. Efeito da variação de níveis de água disponível no solo sobre o crescimento e produção de feijão caupi, vagens e grãos verdes. Horticultura Brasileira, Brasília, v. 22, n. 2, p. 174-177, 2004.

OLIVEIRA, G. A.; ARAÚJO, W. F.; CRUZ, P. L. S.; SILVA, W. L. M.; FERREIRA, G. B. Resposta do feijãocaupi as lâminas de irrigação e as doses de fósforo no cerrado de Roraima. Revista Ciência Agronômica, Fortaleza, v. 42, n. 4, p. 872-882, 2011.

ROCHA, M. M.; CARVALHO, K. J. M.; FREIRE FILHO, F. R.; LOPES, A. C. A.; GOMES, R. L. F.; SOUSA, I. S. Controle genético do comprimento do pedúnculo em feijão-caupi. Pesquisa Agropecuária Brasileira, Brasília, v. 44, n. 3, p. 270-275, 2009.

SIMIDU, H. M.; SÁ, M. E.; SOUZA, L. C. D.; ABRANTES, F. L.; SILVA, M. P.; ARF, O. Efeito do adubo verde e época de semeadura sobre a produtividade do feijão, em plantio direto em região de cerrado. Acta Scientiarum Agronomy, Maringá, v. 32, n. 2, p. 309-315, 2010. 